\title{
Neurological Symptoms in Aortic Dissection: A Challenge for Neurologists
}

\author{
Charly Gaul $^{\text {a }}$ Wenke Dietrich ${ }^{\text {b }}$ Frank Joachim Erbguth ${ }^{\text {b }}$ \\ a Department of Neurology, Martin-Luther University Halle-Wittenberg, Halle/Saale, and \\ ${ }^{b}$ Department of Neurology, Municipal Hospital Nuremberg, Nuremberg, Germany
}

\section{Key Words}

Aortic dissection - Mortality · Neurological symptoms • Thrombolysis

\begin{abstract}
Typically, aortic dissection has to be considered in patients with acute thoracic or abdominal pain and accompanying cardiovascular symptoms. Due to these clinical symptoms, neurologists have not been involved in the routine emergency management of aortic dissection. However, transient or permanent neurological symptoms at onset of aortic dissection are not only frequent (17-40\% of the patients), but often dramatic and may mask the underlying condition. Especially in pain-free dissection (which occurs in 5-15\%) with predominant neurological symptoms diagnosis of aortic dissection can be difficult and delayed. Affecting the outflow of supra-aortal, spinal as well as extremity arteries leads to a variety of neurological symptoms including disturbances of central or peripheral nervous system. Thrombolysis as an emergency stroke therapy without considering aortic dissection may be life-threatening for these patients. Routine chest $\mathrm{X}$-ray and being alert to physical examination findings such as hypotension, asymmetrical pulses or cardiac murmur may reduce risk of delayed diagnosis or misdiagnosis. Neurological symptoms at onset or in the postoperative course of aortic dissection are not necessarily associated with increased mortality.

Copyright $\odot 2008$ S. Karger AG, Basel
\end{abstract}

\section{Introduction}

Michael Ellis DeBakey (born September 7, 1908) who was the pioneer of the treatment of aortic dissections noticed himself on December 31, 2005, to be suffering from painful aortic dissection type II. He initially refused the life-saving operation for several weeks. In the course of disease, he suffered from neurological symptoms before undergoing the operation on February 9, 2006, when he was 97 years old. Following the operation, he was sometimes delirious, sometimes unresponsive, but could be discharged from the hospital on May 16, 2006 [1]. However, aortic dissection is a life-threatening vascular emergency that is frequently and rapidly associated with serious complications and therefore requires urgent surgical therapy. More than one third of all patients with aortic dissection demonstrate signs and symptoms secondary to organ system involvement $[2,3]$. When the ascending aorta is involved, acute aortic insufficiency, pericardial effusion, and cardiac failure are common [3]. Furthermore, the dissection may compress or occlude side branches of the aorta and produce acute ischemia: in arms or legs in $10-20 \%$, kidney in $15 \%$, myocardium in $10 \%$, brain in $5-15 \%$, and mesentery or spinal cord in $3 \%$ [3-5]. The range of presenting clinical features is not only wide but extremely variable, thus making the correct diagnosis challenging. Despite major advances in diagnostic imaging and progress in therapy, the diagnosis of aor-

\section{KARGER}

Fax +41613061234 E-Mail karger@karger.ch www.karger.com (c) 2008 S. Karger AG, Basel

1015-9770/08/0261-0001\$24.50/0

Accessible online at:

www.karger.com/ced
Charly Gaul, MD

Department of Neurology, Martin-Luther-University Halle-Wittenberg

Ernst-Grube-Strasse 40

DE-06097 Halle/Saale (Germany)

Tel. +49 345557 2858, Fax +49 345557 5860, E-Mail charly.gaul@gmx.de 
tic dissection still remains unsuspected in a substantial number of patients (up to $28 \%$ ), and the mortality rate is high [6]. Neurological symptoms at onset of aortic dissection are not only frequent, but often dramatic and may mask the underlying condition. Especially in pain-free dissections with predominant neurological symptoms diagnosis of aortic dissection can be difficult and delayed.

\section{Search Strategy and Selection Criteria}

References for this review were identified by searches of PubMed from 1966 until August 2007 with the terms 'aortic dissection', and 'neurological symptoms', 'stroke', 'ischemic neuropathy', and 'spinal cord ischemia'. Articles were also identified through searches of the authors' own files (including abstract books and supplements) and in current and well-established international textbooks in the field.

\section{Classification and Etiology of Aortic Dissections}

Two factors - an initial event and a structural weakness of the arterial wall (e.g. Marfan's syndrome) - contribute to dissection of the aorta [3]. Usually, dilatation of the aorta or high blood pressure tears the intima. Commencing at this entry, blood enters the media layer resulting in a growing artery wall defection expanding proximally to the heart or distally to the abdominal aorta. Typically, one or more tears in the intima layer allow communication between both lumens. Intramural hematoma without an intimal tear is observed with increasing frequency $[4,7]$. The proximal ascending aorta is vulnerable to dissection because during systole it expands the most and its convexity is repeatedly exposed to maximum arterial pressure [3]. Aortic dissections usually are classified following DeBakey or Standford classification systems based on anatomical location. DeBakey type I dissection originates in the ascending aorta and propagates to the aortic arch and the descending aorta. Type II is completely confined to the ascending aorta. Type III spares the ascending aorta and originates in the descending aorta [8]. Standford type A dissections involve the ascending aorta and type $\mathrm{B}$ dissections occur distal to the left subclavian artery [9]. Isolated dissections of the aortic arch, however, do not fit in this simplified classification and are therefore called non-A, non-B aortic dissection [3].
The typical patient is a male in his seventh decade with a history of hypertension who presents with abrupt onset of thoracic pain [4]. A history of hypertension, which is considered the most common predisposing factor of aortic dissection, is present in 62 to $78 \%$ of patients $[4,6$, 10].

\section{Differential Diagnosis of Aortic Dissection in Typical Presentation}

The majority of patients reports thoracic pain as a typical but nonspecific symptom. Myocardial infarction, pleuritis, or pericarditis as well as pneumothorax have to be considered [11]. Neurological involvement is a helpful aid in differentiating aortic dissection from coronary artery occlusion, in which such findings are uncommon [12].

\section{Atypical Presentation of Aortic Dissections}

Remarkably, chest pain is not an obligatory symptom of aortic dissection, the frequency of pain-free dissections ranges between 5 and $15 \%[4,5,10,13]$. Especially in the context of neurological sequelae of aortic dissection numerous patients without notable pain were reported [5, 14-22]. While Hagan et al. [4] reported that most of their patients who presented with stroke also gave a history of pain, in our own study [5] only two thirds of patients with neurological symptoms at onset of dissection complained of pain, whereas most patients without neurological symptoms (94.4\%) experienced initial pain. Approximately half of all patients who did not report pain showed neurological symptoms only [5]. However, aortic dissection may also present with misleading signs of subarachnoid hemorrhage like major pain in the head or in the neck [5, 10, 23-26]. Therefore, neurologists and internal specialists must be vigilant for aortic dissection in patients with atypical pain and/or pure neurological symptoms.

\section{Neurological Symptoms Caused by Aortic Dissection}

Neurological symptoms associated with aortic dissections are often dramatic and may completely dominate the clinical picture. They can be classified into different groups according to Blanco et al. [27] and attributable to early reports of Weisman and Adams [28] and Scott and 
Fig. 1. Central and peripheral nervous system manifestations of aortic dissection.
TIA

Stroke

TGA-like syndrome

Hypoxic encephalopathy

Horner syndrome

Cardiovocal syndrome

Seizure, disturbed consciousness

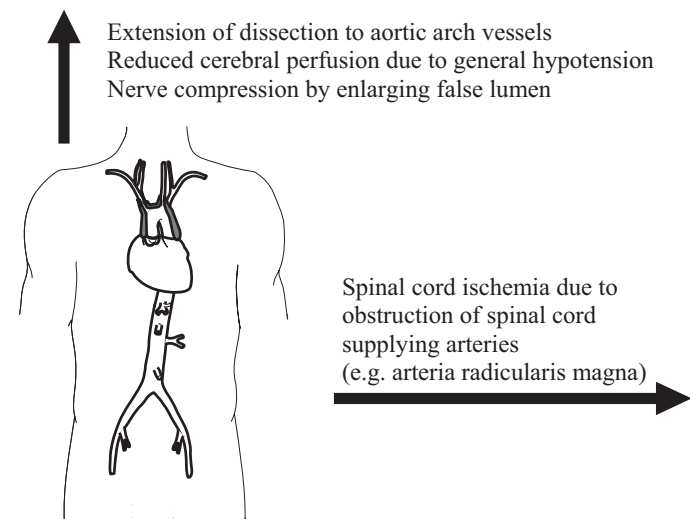

Paraparesis anterior spinal cord syndrome, Brown-Sequard syndrome, progressive myelopathy or transient spinal cord ischemia

Spinal cord ischemia due to

Obstruction of vasa nervorum

Compression of a nerve by the enlarging false lumen

Ischemic neuropathy (paraparesis, polyneuropathy, mononeuropathy)

Ischemic plexopathy

Nerve compression syndrome

Table 1. Initial neurological symptoms in type A aortic dissection

\begin{tabular}{|c|c|c|c|c|c|c|c|}
\hline & $\begin{array}{l}\text { Gaul } \\
\text { et al. [5] }\end{array}$ & $\begin{array}{l}\text { Blanco } \\
\text { et al. [27] }\end{array}$ & $\begin{array}{l}\text { Álvarez } \\
\text { et al. [30] }\end{array}$ & $\begin{array}{l}\text { Meszaros } \\
\text { et al. [13] }\end{array}$ & $\begin{array}{l}\text { Fann } \\
\text { et al. [31] }\end{array}$ & $\begin{array}{l}\text { IRAD } \\
{[51]}\end{array}$ & $\begin{array}{l}\text { Weisman } \\
\text { et al. [28] }\end{array}$ \\
\hline Patients & 102 & 24 & 90 & 75 & 174 & 289 & 38 \\
\hline Type of dissection & A & I & A & $\mathrm{A}$ or $\mathrm{B}$ & A & A & A \\
\hline Neurological symptoms & $30(29.4)$ & $6(25)$ & $21(23)$ & $30(40)$ & * & $*(17)$ & $11(29)$ \\
\hline Ischemic stroke & $16(15.7)$ & $2(8.3)$ & $12(13.3)$ & $24(32)$ & $17(6)$ & $*(6.1)$ & $1(2.6)$ \\
\hline Spinal cord ischemia & $1(1)$ & $1(4.2)$ & $8(8.9)$ & $2(2.7)$ & $*(5)$ & $*$ & $1(2.6)$ \\
\hline Ischemic neuropathy & $11(10.8)$ & $1(4.2)$ & $5(5.6)$ & $4(5.3)$ & $*$ & * & $9(24)$ \\
\hline Hypoxic encephalopathy & $2(2)$ & $2(8.3)$ & $*$ & * & * & $*$ & * \\
\hline Syncope & $6(5.9)$ & * & $3(3.3)$ & * & * & $*(12.7)$ & * \\
\hline
\end{tabular}

* No data available. Numbers in parentheses denote percentages.

Sancetta [29]: (a) persistent or transient ischemic stroke, (b) spinal cord ischemia, (c) ischemic neuropathy, and (d) hypoxic encephalopathy (fig. 1). These symptoms are due to general hypotension or dissection/occlusion of one or more aortic side branches supplying brain, spinal cord or peripheral nerves. The frequency of neurological involvement varies between 17 and 40\% (table 1) $[4,5,13,27,30$, 31]. This variation perhaps can be explained by failure to record a detailed neurological examination in critically ill patients leading to an underestimation of neurological 
complications. Mean age and gender distribution in patients with neurological involvement do not differ from the general population $[5,27]$. Interestingly, neurological findings are frequently evanescent and often fully remitted before admission to the emergency room $[5,32]$. They usually appear at or shortly after the onset of dissection. Rapid improvement in such cases is probably the result of only transient arterial occlusion at the moment of propagation of the dissection. Remarkably, in our study [5] one fourth of the patients with initial neurological symptoms presented a combination of different neurological symptoms: (a) hemiparesis and syncope or tonic-clonic seizure, (b) transient ischemic amnesia and syncope, (c) ischemic neuropathy and seizure, and (d) TGA-plus syndrome.

\section{Symptoms of Brain Involvement}

Symptoms of acute ischemic stroke are the most common initial neurological finding $[5,13,14,17,18,27,30]$. Preoperative strokes tend to be more frequently hemispheric compared with vertebral-basilar location and predominantly right-sided $[5,27,32]$. The explanation for the hemispheric predominance is accounted for the fact that the carotid artery origins are much more vulnerable to the advancing false channel due to their proximity to the aortic arch $[13,27]$. The dominance of right-sided strokes on the other hand occurred despite mostly bilateral common carotid artery dissection. This fact perhaps could be explained by different mechanical dynamics in the progression of the dissecting hematoma [32]. In clinicopathological series, sometimes no brain lesions are found at autopsy, mostly attributable to a very short survival time, not long enough to produce recognizable tissue alterations $[17,32]$.

Disorders of consciousness or syncopes and epileptic seizures frequently occur at the onset of aortic dissection $[4,5,23,32]$. They were present in half of all patients with neurological symptoms in our study [5], while Hagan et al. [4] reported syncopes in $12.7 \%$ of all their patients, this matching to the frequency ranges from 6 to 13\% reported in old series [23]. Syncopes are an unspecific symptom likewise caused by focal brain lesions or global cerebral malperfusion as directly in consequence of cardiac disturbances or acute pain in aortic dissection. Seizures are probably caused by focal lesions or due to a convulsive syncope. Hypoxic encephalopathy often presents with mental status impairment ranging from confusion to loss of consciousness. Hypoxic encephalopathy mostly follows global CNS hypoperfusion secondary to transient or sustained hypo- tension caused by shock from cardiac tamponade, intrapleural or retroperitoneal bleeding, or aortic rupture. The great supra-aortic vessels are often spared [27].

More difficulties in explanation of pathophysiology are caused by exceptional symptoms like transient global amnesia (TGA), which is not generally accepted as an arterial vascular phenomenon. While in patients with TGAplus syndrome (TGA and additional minor neurological symptoms) transient ischemic amnesia is suggested [5, $33,34]$, in patients with pure TGA an underlying stress reaction triggered by the acute pain event is discussed [35-38]. However, TGA-like symptoms are important because TGA may extinguish important details of the patient's recent history. One of the reported patients for instance could not report the sudden onset of severe chest pain, which was the reason for the emergency call, because the episode fell into the retrograde memory gap.

\section{Stroke Treatment with Tissue Plasminogen Activator in the Presence of Acute Aortic Dissection}

With increased early intravenous thrombolytic therapy in acute ischemic stroke or myocardial infarction, misdiagnosis could be fatal. There have been a number of cases of suspected myocardial infarction inadvertently treated with thrombolysis, complicated by extension of dissection into the pericardium, leading to cardiac tamponade and death $[11,15]$. For that reason and because of the high risk of fatal rupture of the ascending aorta or the aortic arch, the guidelines for thrombolysis in myocardial infarction mention aortic dissection as an absolute contraindication $[2,12]$.

Rt-PA must be administered within a very brief time window; therefore, it is important that patients with stroke mimics or major contraindications are identified early [22]. A comprehensive review of the literature with a PubMed database from 1966 to the present revealed only 3 cases of rt-PA given intravenously to persons with acute ischemic stroke resulting from aortic dissection [5, $15,19]$. Two patients died due to cardiac tamponade and intrapleural hemorrhage [5], respectively, due to extending ischemic infarction and intracerebral hemorrhage in the opposite hemisphere [15], the third one was successfully treated with rt-PA and 4 days after thrombolytic therapy by aortic replacement with an uneventful postoperative course [19]. Although rt-PA therapy in patients with solely internal carotid artery dissection has been reported to be feasible [39], the risks of thrombolytic therapy seem to be much higher when the dissection occurs in the aorta. Similar poor outcomes like in patients with myocardial infarction are likely. Because aortic dissec- 
tion is a rare cause of ischemic stroke, the aggressiveness of screening for this entity has to be questioned. An emergent chest X-ray should be considered as a part of acute ischemic stroke protocols as well as paying attention to physical examination findings (hypotension, reduced peripheral pulses, aortic regurgitation murmur) [16].

\section{Involvement of the Supra-Aortic Branches}

Involvement of the major branches of the aortic arch - confirmed by CT or MR angiography, carotid $\mathrm{Du}$ plex, or intraoperative visualization - was found in $43 \%$ of all patients in our study [5] and in $29 \%$ of the autopsied cases by Meszaros et al. [13], most frequently affecting the innominate and carotid arteries because of the proximity to the aortic arch. Blanco et al. [27] found involvement of the supra-aortic branches in 2 of 9 patients with DeBakey type I dissection, but precisely in those with cerebral ischemia, whereas Álvarez Sabin et al. [30] revealed dissection of the supra-aortic vessels in 8 of the 14 patients with cerebral ischemia.

Involvement of the supra-aortic vessels not necessarily leads to ischemic stroke: only one fifth of our patients [5] with dissection of supra-aortic branches presented with preoperative stroke. However, in the preoperative stroke subgroup, the frequency of supra-aortic involvement was $62.5 \%$ [5]. That means, in one-third of all patients with preoperative stroke, ischemic stroke was not caused by narrowing of the supra-aortic vessels, but was caused by other mechanisms such as thromboembolism or severe hypotension.

\section{Cervical Doppler and Duplex Sonographic Findings in Aortic Dissection}

An abnormal signal in the extracranial Doppler sonography due to the movement of the dissection membrane or to aortic regurgitation can reveal the first hint of an underlying aortic dissection [14, 40, 41]. Other frequent ultrasonographic findings include occlusion of one or both common carotid arteries or double lumen in one or both common carotid arteries extending to the carotid bifurcation with hemodynamic relevant stenosis of the common or internal carotid artery as well as subclavian or carotid steal syndrome.

\section{Symptoms of Spinal Cord Involvement}

Spinal cord ischemia on the basis of aortic dissection is a rare syndrome and more common with distal aortic dissections. Spinal cord involvement in patients with aor- tic dissection could be secondary to obstruction of the intercostal and lumbar arteries, the Adamkiewicz artery (arteria radicularis magna), or the thoracic radicular arteries. Clinical manifestations comprise complete spinal cord infarction as well as anterior spinal cord syndrome, Brown-Sequard syndrome, progressive myelopathy or transient spinal cord ischemia $[6,12,17,21,27]$. Most frequently, the middle thoracic spinal cord, the watershed zone between the territories of the artery of Adamkiewicz, and the thoracic radicular artery are affected [6].

\section{Symptoms of Peripheral Nerve Involvement}

Involvement of the peripheral nerves occurs as ischemic neuropathy $[5,6,13,17,27]$ and ischemic plexopathy [42] or due to the direct compression of a nerve by the enlarging false arterial lumen [6]. The latter comprises Horner's syndrome and hoarseness of voice caused by vocal cord paralysis due to compression of the left recurrent laryngeal nerve (cardiovocal syndrome; Ortner's syndrome) $[2,6,27]$.

Ischemic neuropathy is the second common neurological manifestation of dissecting aortic aneurysm [5, $13,28]$. It manifests due to extension of dissection into a major artery of an extremity, interfering with its blood supply. The degree of collateral circulation and threshold differences for ischemic injury probably determine whether only ischemic neuropathy or ischemic necrosis of the extremity will occur [49]. In our study [5], ischemic neuropathy resulted from occlusion of the aortic bifurcation, iliac or femoral arteries, and subclavian artery. Clinical symptoms appear suddenly in all cases and reach their maximum intensity within a few minutes to hours. In most cases, the first symptom is severe pain referred distally into the extremity not following the distribution of nerve trunks. Other typical features are numbness, coldness and paresthesia, pulse deficit, and in severe cases motor deficit amounting in some instances to paralysis.

Acute paraparesis in the context of aortic dissection often occurs due to spinal cord ischemia. In contrast, ischemic neuropathy as the cause of paraparesis is uncommon and presents more likely with monoparesis or unilateral lower extremity numbness. Potential sites of injury in large vessel occlusive disease, as described in previous case reports, include the root, the plexus, the proximal nerve at a 'watershed' region, or multiple distal mononeuropathies [43, 44]. In cat model, experimental thrombosis of the distal aorta led to paresis of the hindlimbs [45]. The 
degree of nerve injury depends on the duration of ischemia. Moderate ischemia has been demonstrated to produce temporary conduction block, likely related to focal edema. More prolonged ischemia may result in axonal loss with wallerian degeneration $[43,46,47]$.

\section{Emergency Diagnostics in Suspected Cases of Aortic Dissection}

Once aortic dissection is suspected, time is a critical factor. In older series, death rate of untreated aortic dissection was $1-2 \%$ per hour after first presentation and approximately $25 \%$ during the first $24 \mathrm{~h}[6,23]$. The diagnosis of aortic dissection can be confirmed by computed tomography, transthoracic or transesophageal echocardiography, magnetic resonance imaging, or aortography (or combination of these studies, positive predictive values in high-risk patients $>85 \%$ for all four diagnostic modalities). The choice of initial imaging modality in most studies reflects availability rather than preference [4]. Transthoracic echocardiography is diagnosed in $75 \%$ of type A dissections [3]. This rapid evaluation can be followed by a single additional diagnostic step before treatment is started. Unstable patients are best evaluated by transesophageal echocardiography in the operating theater, stable patients by computed tomography or magnetic resonance imaging. Aortography is recommended when diminished perfusion of an aortic branch is suspected or when other diagnostics are not available [3]. Although chest radiography lacks sensitivity and specificity for the diagnosis of aortic dissection, it could be helpful for the initial prediction when used in combination with history and clinical examination findings $[6,20,48]$. With increased frequency of early intravenous thrombolytic therapy in suspected acute ischemic stroke or myocardial infarction, misdiagnosis could rapidly be fatal. For safety reasons, a chest X-ray must be considered as a minimum standard in all patients before thrombolytic therapy. Elevated D-dimer plasma concentration may prove a valuable addition in the diagnostic work-up of acute type A aortic dissection [49].

\section{Impact of Prognosis due to Initial Neurological Symptoms}

Different studies provide conflicting evidence concerning the question if the presence of neurological symptoms is an independent predictor of poor outcome or in- hospital death in patients with acute type A aortic dissection. While our study [5], the IRAD (International Registry of Acute Aortic Dissection) [4, 50, 51], and Fann et al. [31] revealed no such correlation, other investigators $[52,53,54]$ identified preoperative neurological deficit as a significant predictor of in-hospital death.

Coma or stroke as part of clinical presentation of acute aortic dissection was generally considered a major contraindication for emergency repair in view of the hazards of extracorporeal circulation and systemic heparinization. But recent studies analysing large cohorts of patients have also failed to identify brain malperfusion as an independent risk factor for an adverse outcome after surgical repair $[5,51,55]$. Although Centofanti et al. [56] identified coma as a preoperative independent predictor of 30-day mortality in a large, single-center study, coma may not represent a contraindication for resuscitative surgery in hemodynamically stable patients, because the literature addressing this specific issue is scarce. Pocar et al. [57] reported five comatose, hemodynamically stable patients with preserved pupillary reactivity and coma duration of less than $12 \mathrm{~h}$ who underwent surgery and recovered without $(n=4)$ or with mild $(n=1)$ neurological sequelae. These findings conflict sharply to the proposals of Álvarez Sabin et al. [30] and Blanco et al. [27] that neurological symptoms per se would indicate an unfavourable prognosis of aortic dissection. Overall in-hospital mortality in the study of Álvarez Sabin et al. [30] was $85.7 \%$ in type A dissections and $100 \%$ in presence of cerebral complications. Blanco et al. [27] reported an overall in-hospital mortality rate of $66.6 \%$ and a mortality rate of $77.7 \%$ in patients with neurological symptoms. However, in both studies overall inhospital mortality rates were clearly higher than reported in most studies (9-36\%) [5, 31, 51-53, 55, 56, 58-60].

Based on the most comprehensive analysis of $682 \mathrm{pa}-$ tients in the IRAD [50], a multivariable risk prediction tool was suggested. Independent preoperative predictors of mortality were: age $>70$ years (OR 1.98), prior cardiac surgery (OR 4.21), hypotension (systolic blood pressure less than $100 \mathrm{~mm} \mathrm{Hg}$ ) or shock (OR 3.23), cardiac tamponade (OR 2.65), migrating pain (OR 2.42), any pulse deficit (OR 1.75), and findings of myocardial ischemia (OR 1.76).

\section{Clinical Implications}

Neurological symptoms at acute onset of type A aortic dissection can be observed in one third of patients without any significant pain. Additionally, in case of aphasia, 
unconsciousness or TGA, patients cannot report chest pain. Therefore the constellation of painfree dissection and dominating neurological sequelae complicates the correct diagnosis. Suggestive clinical signs are: (1) syncopes in combination with transient ischemic amnesia or (2) severe disturbances of consciousness with pronounced focal neurological signs. The occurrence of either of these symptoms in an elderly hypertensive patient with chest pain, shock-like appearance, asymmetrical pulses, or cardiac murmur should suggest the diagnosis of aortic dissection and lead to further diagnostics, especially in patients considered for thrombolytic therapy. Evanescent, but initially dramatic neurological symptoms do not at all point against aortic dissection, in fact more than half of patients show complete remission of symptoms before admission to the emergency room. Unusual combinations of symptoms and signs such as involvement of central and peripheral nervous system or simultaneous occurrence of syncope, seizure, and cerebral, spinal, or peripheral nerve ischemia point to an underlying spreading vascular process such as aortic dissection. Not at least in the presence of apparently harmless constellations like TGA accompanying minor focal signs should be noticed. If aortic dissection is early recognized neurological symptoms are not necessarily associated with an increased mortality. Presence of neurological symptoms, even severe, does not warrant withholding surgery to the patients.

\section{References}

1 Altman, Lawrence K: The Man on the table was 97, but he devised the surgery. New York Times, 2006-12-25.

$\checkmark 2$ Khan IA, Wattanasauwan N, Ansari AW: Painless aortic dissection presenting as hoarseness of voice: cardiovocal syndrome; Ortner's syndrome. Am J Emerg Med 1999; 17:361-363.

-3 Pretre R, von Segesser LK: Aortic dissection. Lancet 1997;349:1461-1464.

4 Hagan PG, Nienaber CA, Isselbacher EM, et al: The International Registry of Acute Aortic Dissection (IRAD): new insights into an old disease. JAMA 2000;283:897-903.

$\checkmark 5$ Gaul C, Dietrich W, Friedrich I, Sirch J, Erbguth FJ: Neurological symptoms in type A aortic dissections. Stroke 2007;38:292-297.

6 Khan IA, Nair CK: Clinical, diagnostic, and management perspectives of aortic dissection. Chest 2002;122:311-328.

$\checkmark 7$ Nienaber CA, von Kodolitsch Y, Petersen B, et al: Intramural hemorrhage of the thoracic aorta: diagnostic and therapeutic implications. Circulation 1995;92:1465-1472.

-8 DeBakey ME, Henley WS, Cooley DA, Beall AC Jr: Surgical management of dissecting aneurysms of the aorta. Thorac Cardiovasc Surg 1965;49:130-148.

-9 Dailey PO, Trueblood HW, Stinson EB, Wuerflein RD, Shumway NE: Management of acute aortic dissections. Ann Thorac Surg 1970;10:237-246

-10 Spittell PC, Spitell JA, Joyce JW, et al: Clinical features and differential diagnosis of aortic dissection: experience with 236 cases (1980 through 1990). Mayo Clin Proc 1993; 68:642-651.

-11 Kamp TJ, Goldschmidt-Clermont PJ, Brinker JA, Resar JR: Myocardial infarction, aortic dissection, and thrombolytic therapy. Am Heart J 1994;128:1234-1237.
12 Beggs AD, Al-Rawi H, Parfitt A: Chest pain fleeting neurological signs. Lancet 2005;365: 1514.

13 Meszaros I, Morocz J, Szlavi J, et al: Epidemiology and clinicopathology of aortic dissection. Chest 2000;117:1271-1278.

14 Etgen T, Langer R, Neff F, Sander K, Conrad B, Sander D: Dopplersonographie mit Hinweis auf fulminante Aortendissektion bei initialem Mediainfarkt. Nervenarzt 2005;76: 976-979.

15 Fessler AJ, Alberts MJ: Stroke treatment with tissue plasminogen activator in the setting of aortic dissection. Neurology 2000;54:1010.

16 Flemming KD, Brown RD: Acute cerebral infarction caused by aortic dissection: caution in the thrombolytic era. Stroke 1999;30: 477-478.

17 Gerber O, Heyer EJ, Vieux U: Painless dissections of the aorta presenting as acute neurologic syndromes. Stroke 1986;17:644-647.

-18 Stanley I, Sharma VK, Tsivgoulis G, Lao AY, Alexandrov AV: Painless aortic dissection with unusual extension into intracranial carotid arteries. Cerebrovasc Dis 2007;24:314315.

19 Ibaraki T, Fukumoto H, Nishimoto Y, Nishimoto M, Suzuki S, Morita H: Surgical management of acute type $\mathrm{A}$ aortic dissection with a complaint of disturbance of consciousness; report of a case. Kyobu Geka 2002;55:1053-1056.

20 Morita S, Shibata M, Nakagawa Y, Yamamoto I, Inokuchi S: Painless acute aortic dissection with a left hemiparesis. Neurocrit Care 2006;4:234-236.

21 Rosen SA: Painless aortic dissection presenting as spinal cord ischemia. Ann Emerg Med 1988;17:840-842.

22 Wright V, Horvath R, Baird AE: Aortic dissection presenting as acute ischemic stroke. Neurology 2003;61:581-582.
23 Hirst AE, Johns VJ, Kime SW: Dissecting aneurysms of the aorta: a review of 505 cases. Medicine 1958;37:217-279.

24 Mathys J, Lachat M, Herren T: Headache as a manifestation of a life-threatening vascular disorder. Headache 2004;44:706-709.

-25 Nohe B, Ernemann U, Tepe G, Ritz R, Bail D: Aortic dissection mimicking subarachnoidal hemorrhage. Anesth Analg 2005;101: 233-234

26 Singh S, Huang JY, Sin K, Charles RA: Headache: an unusual presentation of aortic dissection. Eur J Emerg Med 2007;14:47-49.

-27 Blanco M, Díez-TejedorE, LarreaJL, Ramirez U: Neurologic complications of type I aortic dissection. Acta Neurol Scand 1999;99:232235.

$\checkmark 28$ Weisman AD, Adams RD: Neurologic complications of dissecting aortic aneurysm. Brain 1944;67:69-92.

29 Scott RW, Sancetta SM: Dissecting aneurysm of aorta with hemorrhagic infarction of spinal cord and complete paraplegia. Am Heart J 1949;38:747-756

30 Álvarez Sabín J, Vázquez J, Sala A, Ortega A, Codina Puiggrós A: Manifestaciones neurológicas de los aneurismas disecantes de aorta. Med Clin (Barc) 1989;92:447-449.

31 Fann JI, Smith JA, Miller CD, et al: Surgical management of aortic dissection during a 30-year period. Circulation 1995;92:113121.

32 Chase TN, Rosman NP, Price DL: The cerebral syndromes associated with dissecting aneurysms of the aorta: a clinicopathological study. Brain 1968;9:173-190.

33 Gaul C, Dietrich W, Tomandl B, Neundörfer B, Erbguth FJ: Aortic dissection presenting with transient global amnesia-like symptoms. Neurology 2004;63:2442-2443. 
-34 Hodges JR, Warlow CP: Syndromes of transient amnesia: towards a classification: a study of 153 cases. J Neurol Neurosurg Psychiatry 1990;53:834-843.

35 Bonnet P, Niclot P, Chaussin F, Placide M, Debray MP, Fichelle A: A puzzling case of transient global amnesia. Lancet 2004;364: 554.

>36 Rosenberg GA: Transient global amnesia with a dissecting aortic aneurysm. Arch Neurol 1979;36:255.

>37 Mondon K, Blechet C, Gochard A, Elaroussi D, Fetissof F, De Toffol B, Autret A, Hommet $\mathrm{C}$ : Case of the month: transient global amnesia caused by painless aortic dissection. Emerg Med J 2007;24:63-66.

>38 Pantoni L, Lamassa M, Inzitari D: Transient global amnesia: a review emphasizing pathogenic aspects. Acta Neurol Scand 2000;102: 275-283.

-39 Derex L, Noghoghossian N, Turjman F, et al: Intravenous tPA in acute ischemic stroke related to internal carotid artery dissection. Neurology 2000;54:2159-2161.

-40 Bonnin P, Giannesini C, Amah G, Kevorkian JP, Woimant F, Levy BI: Doppler sonography with dynamic testing in a case of aortic dissection extending to the innominate and right common carotid arteries. Neuroradiology $2003 ; 45: 472-475$.

-41 Lovrencic-Huzjan A, Jurasic MJ, LovrencicPrpic G, Vukovic V, Demarin V: Aortic arch dissection presenting with hemodynamic spectrum of aortic regurgitation on transcranial Doppler. Ultraschall Med 2006;27: 280-283.

42 Lefebvre V, Leduc JJ, Choteau PH: Painless ischemic lumbosacral plexopathy and aortic dissection (letter). J Neurol Neurosurg Psychiatry 1995;58:641.
43 Larson WL, Wald JJ: Foot drop as a harbinger of aortic occlusion. Muscle Nerve 1995; 18:899-903.

44 Le DA, Traynor EN, Ghazvini A: Aortic occlusion causing ischemic neuropathy and paraparesis. Neurology 2004;63:1984.

45 Korthals JK, Maki T, Korthals MA, Prockop LD: Nerve and muscle damage after experimental thrombosis of large artery: electrophysiology and morphology. J Neurol Sci 1996;136:24-30.

46 Kaku DA, Malamut RI, Frey DJ, Parry GJ: Conduction block as an early sign of reversible nerve injury in ischemic monomelic neuropathy. Neurology 1993;43:1126-1130.

47 Parry GJ, Linn DJ: Transient focal conduction block following experimental occlusion of the vasa nervorum. Muscle Nerve 1986;9: 345-348.

48 von Kodolitsch Y, Nienaber CA, Dieckmann $\mathrm{C}$, et al: Chest radiography for the diagnosis of acute aortic syndrome. Am J Med 2004; 116:73-77.

49 Immer FF: Is there a place for D-dimers in acute type A aortic dissection? Heart 2006; 92:727-728.

50 Rampoldi V, Trimarchi S, Eagle KA, et al: Simple risk models to predict surgical mortality in acute type A aortic dissection: the International Registry of Acute Aortic Dissection score. Ann Thorac Surg 2007;83:5561

51 Trimarchi S, Nienaber CA, Rampoldi V, et al: Contemporary results of surgery in acute type A aortic dissection: The International Registry of Acute Aortic Dissection experience. J Thorac Cardiovasc Surg 2005;129: 112-122.
52 Pansini S, Gagliardotto PV, Pompei E, et al: Early and late risk factors in surgical treatment of acute type A aortic dissection. Ann Thorac Surg 1998;66:779-784.

53 Ehrlich MP, Ergin A, McCullough JN, et al: Results of immediate surgical treatment of all acute type A dissections. Circulation 2000;102:III248-III252.

54 Chirillo F, Marchiori MC, Andriolo L, et al: Outcome of 290 patients with aortic dissection: a 12-year multicentre experience. Eur Heart J 1990;11:311-319.

55 Chiappini B, Schepens M, Tan E, et al: Early and late outcomes of acute type A aortic dissection: analysis of risk factors in 487 consecutive patients. Eur Heart J 2005;26:180186.

56 Centofanti P, Flocco R, Ceresa F, et al: Is surgery always mandatory for type A aortic dissection? Ann Thorac Surg 2006;82:16581664.

57 Pocar M, Passolunghi D, Moneta A, Mattioli R, Donatelli F: Coma might not preclude emergency operation in acute aortic dissection. Ann Thorac Surg 2006;81:1348-1351.

58 Sinatra R, Melina G, Pulitani I, Fiorani B, Ruvolo G, Marino B: Emergency operation for acute type A aortic dissection: neurologic complications and early mortality. Ann Thorac Surg 2001;71:33-38.

59 Bavaria JE, Pochettino A, Brinster DR, et al: New paradigms and improved results for the surgical treatment of acute type A dissection. Ann Surg 2001;234:336-343.

60 Safi HJ, Miller CC, Reardon MJ, et al: Operation for acute and chronic aortic dissection: recent outcome with regard to neurologic deficit and early death. Ann Thorac Surg 1998;66:402-411. 